\title{
HUBUNGAN ANTARA POLA ASUH ORANG TUA DENGAN KEMAMPUAN TOILET TRAINING ANAK USIA PRA SEKOLAH DI BANJAR KUTUH KELOD UBUD
}

\author{
Oktaviari, Ni Kadek Win ${ }^{1}$; Dewi, Ni Luh Made Asri ${ }^{2 *}$; Astini, Putu Susy N.A ${ }^{3}$; \\ Widayati, Kurniasih $^{4}$ \\ ${ }^{1,2,4}$ Akademi Keperawatan Kesdam IX/Udayana \\ ${ }^{4}$ Politeknik Kesehatan Denpasar \\ *Korespondensi : $\underline{\text { madeasri85@gmail.com }}$
}

\begin{abstract}
Background: Toilet training is an attempt to train children to be able to control bowel movements. In Indonesia, it was found that $16 \%$ of children aged 6 years were still unable to do toilet training independently. One of the important factors in the success of children in doing toilet training is the parenting style applied by parents in educating children at home. Objective: to find out the relationship between parenting style and toilet training ability in pre-school aged children in Kutuh Kelod Banjar Ubud. Method: This study used an observational analysis design with a cross sectional approach. The study population was pre-school age children in Banjar Kutuh Kelod Ubud with sampling techniques using purposive samling. The instrument of this study used the observation sheet toilet training ability and parenting questionnaire. Analysis of toilet training capabilities with parenting using the Spearmans Rho test. Results: The study showed that most of the parents' parenting styles were democratic as many as 24 people (40\%). The results of the Spearmans Rho test were parenting and toilet training abilities with a value of $p=0,000$. Conclusion: This study found that there was a significant relationship between parenting care and toilet training abilities of preschoolers.
\end{abstract}

Keywords: Parenting; toilet training; pre-school children

ABSTRAK

Latar belakang: Toilet training merupakan usaha untuk melatih anak agar mampu mengontrol dalam melakukan buang air besar. Di Indonesia sendiri ditemukan sebanyak $16 \%$ anak usia 6 tahun masih tidak mampu melakukan toilet training secara mandiri. Salah satu faktor penting keberhasilan anak dalam melakukan toilet training adalah pola asuh yang diterapkan orang tua dalam mendidik anak di rumah. Tujuan penelitian untuk mengatahui hubungan pola asuh orang tua dengan kemampuan toilet training pada anak usia pra sekolah di Banjar Kutuh Kelod Ubud. Metode: Penelitian ini ini menggunakan desain analisis observasional dengan pendekatan cross sectional. 
Populasi penelitian adalah anak usia pra sekolah di Banjar Kutuh Kelod Ubud dengan teknik pengambilan sampel menggunakan purposive sampling. Instrument penelitian ini menggunakan lembar observasi kemampuan toilet training dan kuesioner pola asuh orang tua. Analisis kemampuan toilet training dengan pola asuh orang tua menggunakan uji Spearman's Rho. Hasil: Penelitian menunjukkan kbahwa sebagian besar pola asuh orang tua responden adalah demokratis sebanyak 24 orang (40\%). Hasil analisis uji Spearman's Rho pola asuh dan kemampuan toilet training dengan nilai $p=0,000$. Kesimpulan: Penelitian ini menemukan bahwa terdapat hubungan signifikan pola asuh orang tua dan kemampuan toilet training anak usia prasekolah.

Kata kunci: Pola asuh; toilet training; anak usia pra sekolah

\section{PENDAHULUAN}

Usia prasekolah merupakan usia yang sangat penting untuk perkembangan anak. Pada masa ini, anak mulai mengalami perkembangan kognitif dan belajar mandiri dalam melakukan sesuatu. Kegagalan pada proses ini, akan berdampak pada perkembangan anak selanjutnya (Nursalam dkk, 2005). Salah satu kemandirian yang harus dicapai anak prasekolah adalah kemampuan dalam toileting training (Hidayat, 2008). Toilet training merupakan suatu usaha untuk melatih anak agar mampu mengontrol dalam melakukan buang air kecil dan buang air besar (Hidayat, 2008).

Perkembangan anak prasekolah salah satu perkembangan psikoseksual adalah mestimulasi anak untuk melakukan toilet training. Toilet training juga dikenalkan pada si kecil sejak dini, yaitu usia 1 s/d 3 tahun. Toileting training dilakukan pada anak ketika masuk fase kemandirian (Hidayat, 2008). Pelatihan BAB biasanya mulai umur 2 sampai 3 tahun dan pelatihan BAK ketika anak umur 3 sampai 4 tahun. Sehingga BAB atau BAK pada anak usia dibawah 2 tahun masih dianggap wajar, hal ini disebabkan karena anak belum bisa mengontrol otot pembuangan secara sempurna. Tetapi tidak jarang kebiasaan mengompol masih dibawa sampai umur 4-6 tahun. Di Indonesia sendiri ditemukan sebanyak 16\% anak usia 6 tahun masih tidak mampu melakukan toilet training secara mandiri. Berdasarkan studi pendahuluan di Banjar Kutuh Kelod Ubud ditemukan sekitar 10\% dari 60 anak usia prasekolah (1-6 tahun) mengalami kegagalan dalam toilet training yaitu berupa eneurisis (mengompol saat malam hari). 
Keberhasilan toilet training terjadi karena ada banyak faktor diantaranya adalah umur, sex, budaya, motivasi orang tua, Kesiapan anak secara fisik, psikologis maupun secara intelektual. Selain itu salah satunya faktor penting keberhasilan toilet training adalah pola asuh yang diterapkan orang tua dalam mendidik anak di rumah (Nursalam dkk, 2005, Supartini 2004). Pola asuh orang tua adalah pola perilaku orang tua yang diterapkan pada anak dan bersifat relatif konsisten dari waktu ke waktu. Pola perilaku ini dapat dirasakan oleh anak secara negatif maupun positif (Petranto, 2005).

Suatu penelitian dari Rosmiani (2005), tentang Pengaruh Pola Asuh Anak Usia Balita terhadap Perkembangan Tingkah Laku Anak di Taman Penitipan Anak Melati Universitas Diponegoro Semarang dengan menggunakan metode survei dan observasi melalui teknik analisis regresi satu prediktor menyatakan bahwa pola asuh positif untuk anak usia balita mempengaruhi perkembangan tingkah laku anak di taman penitipan anak yang dilakukan oleh para pengasuh di Taman Penitipan Anak Melati Universitas Diponegoro Semarang. Penelitian ini juga didukung oleh penelitian yang dilakukan Hendra (2008), yang menemukan perbedaan pendidikan yang diberikan terhadap anak akan mempengaruhi kemandirian toileting anak.

Tujuan penelitian ini bertujuan untuk mengetahui hubungan pola asuh orang tua dengan kemampuan toilet training pada anak usia pra sekolah di Banjar Kutuh Kelod Ubud

\section{METODE}

Penelitian ini menggunakan desain analisis observasional dengan pendekatan cross sectional. Populasi penelitian ini adalah anak usia pra sekolah di Banjar Kutuh Kelod Ubud dengan teknik pengambilan sampel menggunakan Purposive Sampling. Instrument penelitian ini menggunakan lembar observasi kemampuan toilet training dan kuesioner pola asuh orang tua. Analisis kemampuan toilet training dengan pola asuh orang tua menggunakan uji Spearmen's Rho. 


\section{HASIL}

Tabel 1. Distribusi Frekuensi Responden Berdasarkan Umur

\begin{tabular}{cccc}
\hline No & Umur & Frekuensi & Presentase (\%) \\
\hline 1 & $36-48$ bulan & 35 & 58 \\
2 & $49-60$ bulan & 24 & 42 \\
\hline
\end{tabular}

Pada tabel 1 menunjukkan bahwa sebagian umur responden pada rentang umur 36-48 bulan sebanyak 35 orang (58\%) dan responden pada rentang umur 49-60 bulan sebanyak 24 orang $(42 \%)$.

Tabel 2. Distribusi Frekuensi Responden Berdasarkan Jenis Kelamin

\begin{tabular}{cccc}
\hline No & Jenis Kelamin & Frekuensi & Presentase (\%) \\
\hline 1 & Laki-laki & 24 & 40 \\
2 & Perempuan & 36 & 60 \\
\hline
\end{tabular}

Pada tabel 2 menunjukkan bahwa sebagian besar jenis kelamin ialah perempuan sebanyak 36 responden (60\%) dan jenis kelamin laki-laki sebanyak 24 responden $(40 \%)$.

Tabel 3. Distribusi Frekuensi Responden Berdasarkan Pola Asuh

\begin{tabular}{cccc} 
No & Pola Asuh & Frekuensi & Prosentase (\%) \\
\hline 1 & Demokratis & 24 & 40 \\
2 & Otoriter & 12 & 20 \\
3 & Permisif & 20 & 33 \\
4 & Penelantar & 4 & 7 \\
\hline
\end{tabular}

Pada tabel 3 menunjukkan bahwa sebagian besar responden memiliki pola asuh demokratis sebanyak 24 orang (40\%), pola asuh otoriter sebanyak 12 orang (20\%), pola asuh permisif sebanyak 20 orang (33\%) dan pola asuh penelantar sebanyak 4 orang (7\%).

Tabel 4. Distribusi Frekuensi Responden Berdasarkan Kemampuan Toilet Training

\begin{tabular}{cccc} 
No & Kemampuan Toilet Training & Frekuensi & Prosentase (\%) \\
\hline 1 & Baik & 28 & 63 \\
2 & Cukup & 12 & 20 \\
3 & Kurang & 10 & 17 \\
\hline
\end{tabular}


Pada tabel 4. Menunjukkan bahwa sebagian besar kemampuan toilet training responden baik sebanyak 28 anak (63\%), cukup sebanyak 12 anak (20\%) dan kurang sebanyak 10 anak (17\%).

Tabel 5. Kemampuan Toilet Training Berdasarkan Pola Asuh

\begin{tabular}{|c|c|c|c|c|c|c|c|c|c|}
\hline \multirow{3}{*}{ No } & \multirow{3}{*}{ Pola Asuh } & \multicolumn{6}{|c|}{ Kemampuan Toilet Training } & \multirow{2}{*}{\multicolumn{2}{|c|}{ Total }} \\
\hline & & \multicolumn{2}{|c|}{ Baik } & \multicolumn{2}{|c|}{ Cukup } & \multicolumn{2}{|c|}{ Kurang } & & \\
\hline & & $\mathbf{n}$ & $\%$ & $\mathbf{n}$ & $\%$ & $\mathbf{n}$ & $\%$ & $\mathbf{n}$ & $\%$ \\
\hline 1 & Demokratis & 20 & 33,3 & 4 & 6,7 & 0 & 0 & 24 & 40 \\
\hline 2 & Otoriter & 10 & 16,7 & 2 & 3,3 & 0 & 0 & 12 & 20 \\
\hline 3 & Permisif & 7 & 11,7 & 4 & 6,7 & 9 & 15 & 20 & 33,4 \\
\hline 4 & Penelantar & 1 & 1,7 & 2 & 3,3 & 1 & 1,7 & 4 & 6,7 \\
\hline & Total & 38 & 63,3 & 12 & 20 & 10 & 16,7 & 60 & 100 \\
\hline
\end{tabular}

Pada tabel 5 menunjukkan hasil analisis pola asuh berdasarkan kemampuan toilet training bahwa sebagian besar responden dengan pola asuh demokratis sebanyak 20 anak $(33,3 \%)$ memiliki kemampuan toilet training baik. Hasil uji statistik menunjukkan bahwa ada hubungan yang signifikan antara pola asuh dan kemampuan toilet training $(p=0,000)$.

\section{PEMBAHASAN}

Pola asuh orang tua adalah pola perilaku orang tua yang diterapkan pada anak dan bersifat relatif konsisten dari waktu ke waktu. Pola perilaku ini dapat dirasakan oleh anak, secara negatif maupun positif dan pada dasarnya merupakan model atau cara orang tua memberikan pendidikan kepada anaknya di dalam keluarga. Pendapat ini memandang peran orang tua dalam mendidik anak. Dalam melaksanakan fungsi pendidikan ini setiap orang tua menerapkan cara atau model tertentu sesuai dengan harapan orang tua terhadap perilaku anak (Suanathara, 2005; Petranto, 2005).

Pada penelitian ini dilakukan pengumpulan data dengan kuisioner pola asuh orang tua. Dari hasil analisa deskriptif diperoleh paling banyak menerapkan pola asuh demokratis yaitu sebanyak 24 orang $(40 \%)$ dan 20 orang (33\%) menerapkan pola asuh permisif dan sebanyak 12 orang (20\%) yang menerapkan pola asuh otoriter dan paling sedikit menerapkan pola asuh penelantar yaitu 4 orang $(7 \%)$. 
Variabel kedua yang diteliti peneliti adalah kemampuan toilet training. Kemampuan toilet training anak usia prasekolah di Banjar Kutuh Kelod Ubud 38 orang (63\%) dengan tingkat kemampuan baik, 12 orang (20\%) dengan tingkat kemampuan cukup, dan sisanya dengan tingkat kemampuan kurang sebanyak 10 $\operatorname{orang}(17 \%)$.

Penelitian ini menggunakan uji Spearman's Rho untuk mengetahui hubungan antara pola asuh orang tua dengan kemampuan toilet training pada anak usia prasekolah di Banjar Kutuh Kelod Ubud. Dari hasil analisa statistik diperoleh p value 0,000 atau $\mathrm{p}<0,05$ yang atinya Ho ditolak atau ada hubungan antara pola asuh orang tua dengan kemampuan toilet training. Dari hasil uji Spearman's Rho juga diperoleh nilai correlation coffecient sebesar 0,508 yang artinya adanya hubungan sedang $(0,40-0,599)$ dan positif yang artinya jika pola asuh ibu mengarah ke pola asuh demokratis kemampuan toilet trainig anak akan lebih baik. Hal ini di dukung penelitian yang dilakukan Endra (2011), ditemukan pola asuh orang tua akan mempengaruhi perilaku anak khususnya pada anak remaja.

Hasil dari tabel silang ibu dengan pola asuh demokratis menunjukkan dari 24 responden paling banyak yaitu 20 diantaranya memiliki kemampuan toilet training baik, 4 diantaranya anaknya memiliki kemampuan toilet training cukup, dan tidak ada responden dengan kemampuan toilet buruk. Begitu juga dengan kemampuan toilet training pada orang tua yang menerapkan pola asuh permisif anaknya paling banyak yaitu 20 dari 9 responden memiliki kemampuan toilet training kurang, 7 responden dengan kemampuan toilet training baik, dan 4 dengan kemampuan toilet training cukup. Berbeda dengan orang tua yang menerapkan pola asuh otoriter anaknya paling banyak yaitu 10 dari 12 responden memiliki toilet training baik, 2 responden dengan kemampuan toilet training cukup dan tidak ada responden dengan kemampuan toilet training kurang.. Pada orang tua yang menerapkan pola asuh penelatar ditemukan 1 dari 2 responden dengan kemampuan toilet training baik, 2 cukup dan 1 dengan kemampuan toilet training buruk. 
Pola asuh demokratis dan otoriter yang diterapkan oleh orang tua di Banjar Kutuh Kelod Ubud dalam penelitian ini ditemukan sebagai pola asuh yang paling banyak ditemukan anak prasekolah memiliki kemampuan toilet training baik dan hanya sebagian kecil dengan kemampuan toilet training cukup. Pola asuh demokratis merupakan pola asuh positif seperti orang tua bersikap rasional kepada anak, memberikan kebebasan sekaligus tanggung jawab, komunikasi terbuka dan komunikasi dua arah dan pendekatan bersifat hangat dan kondusif, melibatkan anak dalam setiap perkembangannya (Petranto, 2007). Karakteristik anak pada pola asuh positif yaitu anak menjadi mandiri, dapat mengontrol diri dalam mengontrol kemih dan defekasi. Selain itu anak akan memiliki kepercayaan diri yang bagus yang dapat mendukung perkembangan selanjutnya (Petranto, 2007). Perkembangan toilet yang tercapai dengan baik juga akan mendukung perlakuan orang tua dalam mengasuh anak selanjutnya (Hidayat, 2005). Menurut penelitian yang dilakukan oleh Arik (2011), pola asuh yang diterapkan pada anak di TPA (tempat penitipan anak) berhubungan dengan kemandirian toilet training pada anak. Pola asuh positif akan memberikan dampak perkembangan toilet training anak yang baik sedangkan pola asuh negative dapat menghambat kemandirian toilet training anak.

Pola asuh otoriter merupakan Pola asuh yang cenderung menetapkan standar yang mutlak harus dituruti, biasanya dibarengi dengan ancaman-ancaman. Orang tua tipe ini cenderung memaksa, pemerintah, menghukum. Apabila anak tidak mau melakukan apa yang dikatakan oleh orang tua, maka orang tua tipe ini tidak segan menghukum anak. Orang tua tipe ini juga tidak mengenal kompromi dan dalam komunikasi biasanya bersifat satu arah. Orang tua tipe ini tidak memerlukan umpan balik dari anaknya untuk mengerti mengenai anaknya. Sehingga terkadang orag tua dengan pola asuh ini jika ajaran toileting diterapkan orang tua benar akan memaksa anak menuruti kemauan orang Tua. Hal ini didukung oleh penelitian yang dilakukan Faidah (2009) bahwa pada pola asuh otoriter juga ditemukan anak dengan kemampuan toilet training yang baik. Tetapi pola asuh otoriter akan memberikan terbentuknya kemampuan yang berbeda dengan pola asuh demokratis yaitu 
kemampuan toilet training yang terbentuk terjadi lebih karena keterpaksaan (Sadri, 2008).

Kemampuan toilet training pada pola asuh pemisif dan penelantar ditemukan kemampuan toilet training anak prasekolah adalah kemampuan toilet training cukup dan buruk. Hal ini didukung oleh penelitian yang dilakukan Sadri (2008) yang menemukan pada pola asuh orang tua penelantar dan permisif ditemukan lebih mengarah ke kemandirian prilaku yang lebih rendah.

Pola asuh ini memberikan pengawasan yang sangat longgar. Memberikan kesempatan pada anaknya untuk melakukan sesuatu tanpa pengawasan yang cukup darinya. Mereka cenderung tidak menegur atau memperingatkan anak apabila anak sedang dalam bahaya, dan sangat sedikit bimbingan yang diberikan oleh mereka. Namun orang tua tipe ini biasanya bersifat hangat, sehingga seringkali disukai oleh anak tetapi akan embentuk anak yang terkantung terhadap orang tua dan dalam perkembangannya anak tidak akan bisa mengambil keputusan sendiri dan berdampak terhadap kemandirian anak selanjutnya (Shochib, 2000).

Pola asuh penelantar merupakan tipe orang tua yang memberikan waktu dan biaya yang sangat minim pada anak-anaknya. Waktu mereka banyak digunakan untuk keperluan pribadi mereka, seperti bekerja, dan juga kadang kala biaya pun dihemathemat untuk anak mereka. Termasuk dalam tipe ini adalah perilaku penelantar secara fisik dan psikis pada ibu yang depresi. Ibu yang depresi pada umumnya tidak mampu memberikan perhatian fisik maupun psikis pada anak-anaknya. Kontak anak dan orang tua akan kurang. Peranan orang tua sebagai pendidik dalam pola asuh ini tidak berjalan dengan maksimal sehingga anak cenderung berkembang sendiri. Kemandirian bisa tidak dibentuk dengan baik jika anak tidak mampu belajar tanpa orang tua dengan baik (Nuraeni, 2006).

\section{SIMPULAN DAN SARAN}

Berdasarkan hasil penelitian dan pembahasan maka dapat disimpulkan bahwa penerapan pola asuh orang tua memiliki hubungan signifikan kemampuan toilet training artinya pola asuh mempengaruhi kemampuan anak salah satunya 
kemampuan toilet training. Hasil penelitian ini dapat digunakan sebagai data ilmiah tentang pola asuh dan peneliti menganggap perlu dilakukan penelitian lebih mendalam tentang faktor-faktor yang mempengaruhi kemampuan anak dalam toilet training.

\section{UCAPAN TERIMA KASIH}

Penulis mengucapkan terima kasih kepada institusi Akper Kesdam IX/Udayana yang telah memberikan dukungan dalam penelitian ini, TK Maria Fatima Jembrana Bali yang telah memberikan kesempatan untuk melakukan penelitian, dan tim penelitian Akper Kesdam IX/Udayana.

\section{DAFTAR PUSTAKA}

Hidayat, A. (2008). Pengantar Ilmu Keperawatan Anak. Jakarta: Salemba Medika

Nursalam, dkk. (2005). Asuhan Keperawatan Bayi dan Anak (untuk perawat dan bidan) Edisi I. Jakarta: Salemba Medika

Petranto I. (2005). Pola Asuh Anak. http://www.polaasuhanak.com.Asscesed, 8th April.

Shochib, M. (2000). Pola Asuh Orang Tua dalam Membantu Anak Mengembangkan Disiplin Diri. Jakarta: Rineka Cipta

Supartini, Y. (2004). Buku Ajar Konsep Dasar Keperawatan Anak. Jakarta: EGC 